Revue des patrimoines

23 | 2014

Le patrimoine dans la Grande Guerre

\title{
Le Patrimoine dans la Grande Guerre
}

Éditorial

Jean-Charles Cappronnier, Elsa Marguin-Hamon et Paul Smith

\section{CpenEdition}

Journals

Édition électronique

URL : http://journals.openedition.org/insitu/10972

DOI : 10.4000/insitu. 10972

ISSN : 1630-7305

Éditeur

Ministère de la Culture

\section{Référence électronique}

Jean-Charles Cappronnier, Elsa Marguin-Hamon et Paul Smith, « Le Patrimoine dans la Grande Guerre », In Situ [En ligne], 23 | 2014, mis en ligne le 03 mars 2014, consulté le 22 septembre 2020. URL :

http://journals.openedition.org/insitu/10972 ; DOI : https://doi.org/10.4000/insitu.10972

Ce document a été généré automatiquement le 22 septembre 2020.

\section{(c) $(1) \odot$}

In Situ Revues des patrimoines est mis à disposition selon les termes de la licence Creative Commons Attribution - Pas d'Utilisation Commerciale - Pas de Modification 4.0 International. 


\section{Le Patrimoine dans la Grande Guerre}

Éditorial

Jean-Charles Cappronnier, Elsa Marguin-Hamon et Paul Smith

1 En ce début de l'année 2014, à l'heure où de très nombreuses initiatives contribuent à commémorer la Première Guerre mondiale en France et dans le monde ${ }^{1}$, la direction générale des Patrimoines au ministère de la Culture et de la Communication se devait d'initier une réflexion sur le patrimoine et ce conflit, sous la double interrogation du patrimoine dans le conflit - la cathédrale de Reims, par exemple - et le patrimoine généré et légué par le conflit, comme les monuments aux morts. Le succès remporté par l'appel à contributions sur ces deux thèmes lancé au printemps 2013 a permis la publication d'un numéro de la revue In Situ intitulé «Le Patrimoine dans la Grande Guerre ». Ce premier numéro sera suivi d'un second consacré, lui, au patrimoine produit par la guerre, à sa valeur et à sa portée mémorielle.

2 Il s'agit donc dans un premier temps de cerner l'impact singulier de la guerre sur le patrimoine, compris dans le sens le plus large : paysages, sites, bâtiments, patrimoine mobilier et œuvres d'art, archives écrites, images, institutions... Nous l'envisageons sous l'aspect des destructions ou des dommages que ce patrimoine subit, mais aussi des mesures de protection et de prévention mises en œuvre durant la période même, sous l'égide de l'administration française, mais aussi à l'initiative des autorités allemandes. 
Figure 1

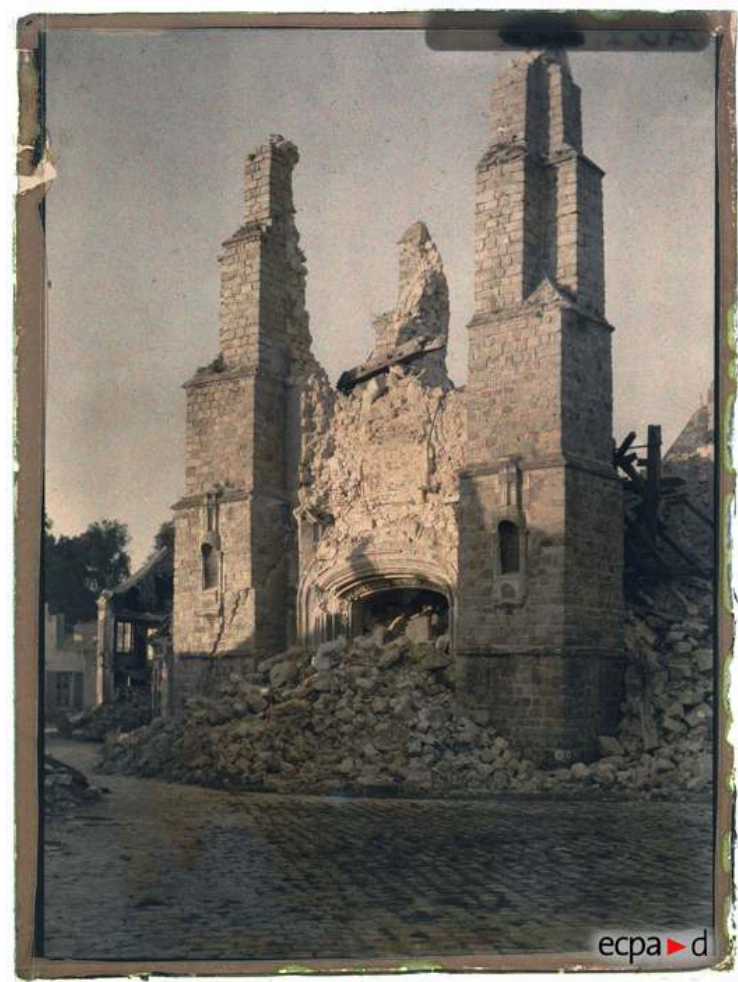

Chauny (Aisne), clocher de l'église Saint-Martin.

Phot. Cuville, Fernand. (C) ECPAD. 24 septembre 1917. Réf. AUL 429.

3 Notons, sans prétendre en embrasser la totalité dans cet éditorial, la variété des champs explorés. Se trouvent ainsi mises en lumière les méthodes adoptées et l'œuvre accomplie par des archéologues allemands en Alsace durant le temps du conflit, allant jusqu'à la publication scientifique des découvertes. Du côté français, pilotées par l'administration centrale et dans le souvenir des pertes subies en 1870 , des mesures sont prises par les archivistes pour sauver les fonds réputés les plus précieux dans les différents dépôts des zones proches du front.

Aux Archives nationales, un fonds peu connu, celui du Séquestre général des biens restitués par les Allemands, jette une lumière nouvelle sur le pillage des œuvres d'art et des objets mobiliers dans les régions occupées. Les œuvres et les monuments "suppliciés » deviennent très vite un outil de propagande, accréditant l'image d'un ennemi barbare, et se trouvent de ce fait tout particulièrement valorisés au sein du musée de Sculpture comparée (l'actuel musée des Monuments français). Le rôle et l'initiative de Camille Enlart, directeur du musée, sont à cet égard déterminants, et il sait largement recourir à la photographie pour susciter le recueillement et la ferveur de visiteurs dont le sentiment patriotique doit sortir raffermi. Aux photographies du musée d'Enlart vient s'ajouter, lors de l'exposition du Petit Palais en 1916, le spectacle des vestiges mutilés, manifestation organisée par Paul Ginisty, journaliste et directeur de théâtre, sous le patronage du sous-secrétariat d'État aux Beaux-Arts: cette opération de grande ampleur est dans sa totalité destinée à dénoncer les «atrocités allemandes ».

5 Du conflit émerge, sur le plan international, une conscience patrimoniale inédite, dont témoignent les débats parfois vifs qui opposent, sous l'égide de la Société des Nations, 
les experts de l'office international des Musées, défenseurs d'un patrimoine partagé et mondial, à protéger par tous, aux nationalistes d'une part et, d'autre part, aux tenants d'un cadre juridique minimal s'appliquant aux seules destructions de guerre. Dès le début des hostilités, d'ailleurs, ces destructions de guerre provoquent un débat sur la préservation d'un patrimoine en ruine, des monuments mutilés chargés de témoigner, après la guerre, de la «barbarie allemande». Se pose également la question "d'un tourisme " de guerre, de la patrimonialisation de certains vestiges significatifs des champs de bataille. Les quatre années du conflit mettent à rude épreuve toutes les doctrines des Monuments historiques.

6 Soulignons, enfin, l'importance de la photographie, qui, grâce à des appareils de poche, est dorénavant à la portée des soldats eux-mêmes, nous léguant un patrimoine d'images personnelles des plus variées. Du côté officiel, le fonds de la section photographique et cinématographique de l'armée peut offrir un inventaire en images du patrimoine picard détruit lors du repli des troupes allemandes en 1917, inventaire qui nourrit la propagande mais qui a aussi son utilité pour les travaux de restauration de l'après-guerre. Ce même fonds permet également de documenter un aspect crucial du conflit, l'effort patriotique des usines de guerre...

Figure 2

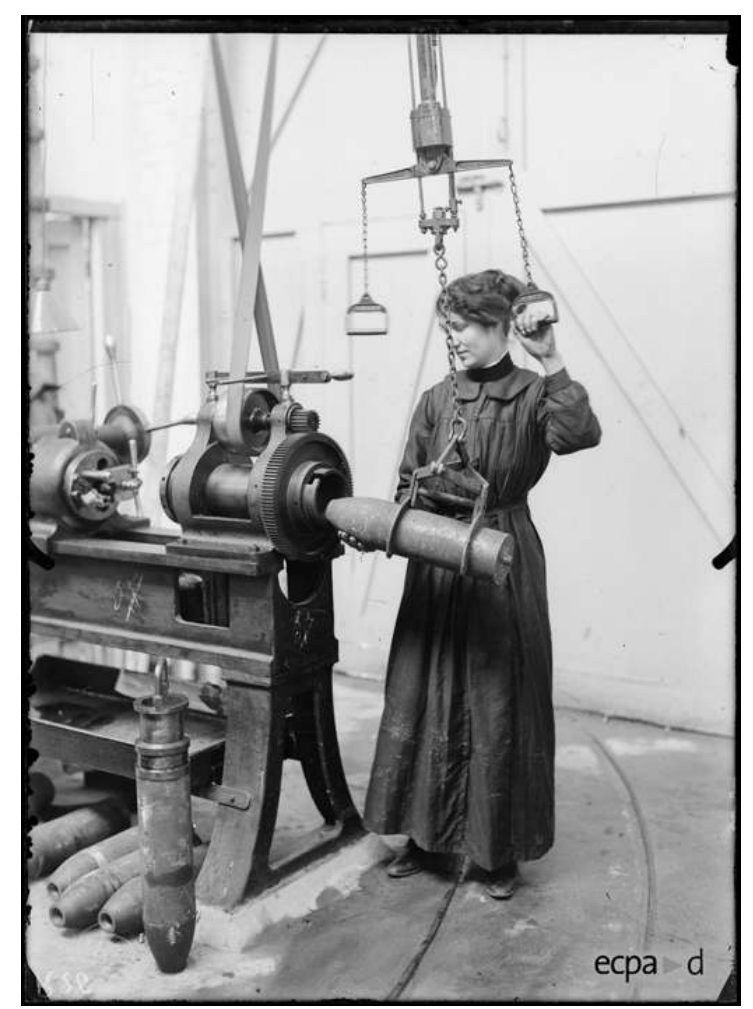

Usine Vedovell, Priestley et Cie (ateliers de construction électrique, 160 rue Saint-Charles, Paris) Vérification du volume intérieur des obus.

Phot. Ribar. (c) ECPAD, janvier 1916, Réf. SPA 3 R 26.

7 Toutes ces contributions dressent un tableau aussi divers que riche du patrimoine pendant la Première Guerre mondiale. C'est un patrimoine blessé, sauvé, sanctuarisé, mais aussi instrumentalisé au service de la propagande. En caractérisant la barbarie d'un ennemi vite assimilé au Vandale des temps anciens, par opposition à la civilisation 
latine et chrétienne que représenterait la France éternelle, cette propagande fait le lit des nationalismes et de l'esprit de revanche qui triomphe à Versailles en 1919, et, en définitive, participe d'une conception de la guerre où l'identification de l'adversaire au mal absolu autorise la totalisation du conflit et dessine les contours d'un siècle de sang ${ }^{2}$.

\section{NOTES}

1. - Voir le portail officiel de la Mission du centenaire 14-18: http://centenaire.org/fr.

2. - L'équipe d'In Situ tient à remercier très vivement Catherine Gros pour sa relecture des articles de ce numéro.

\section{AUTEURS}

\section{JEAN-CHARLES CAPPRONNIER}

conservateur du patrimoine, directeur-adjoint des archives départementales de Meurthe-etMoselle jccappronnier@cg54.fr

\section{ELSA MARGUIN-HAMON}

conservateur du patrimoine, direction des archives nationales, direction des publics, département de l'action culturelle et éducative Musée des Archives nationales elsa.marguin@culture.gouv.fr

\section{PAUL SMITH}

ingénieur d'études, chercheur au département du pilotage de la recherche et de la politique scientifique, Direction générale des patrimoines paul.smith@culture.gouv.fr 